\title{
Electrospun Poly(methyl Methacrylate)/Polyaniline Blend Nanofibres with Enhanced Toxic Gas Sensing at Room Temperature
}

\author{
Rajashree Anwane and Subhash Kondawar* \\ Department of Physics, Rashtrasant Tukadoji Maharaj Nagpur University, \\ Amravati Road, Nagpur, Maharashtra 440033, India \\ ${ }^{*}$ Corresponding author: sbkondawar@yahoo.co.in
}

Published online: 25 April 2018

To cite this article: Anwane, R. \& Kondawar, S. (2018). Electrospun poly(methyl methacrylate)/polyaniline blend nanofibres with enhanced toxic gas sensing at room temperature. J. Phys. Sci., 29(1), 101-119, https://doi.org/10.21315/jps2018.29.1.7

To link to this article: https://doi.org/10.21315/jps2018.29.1.7

\begin{abstract}
Continuous progress in the methods of preparation of new materials for sensing of toxic gases has attracted considerable interest due to environmental problems. In the present investigation, poly(methylmethacrylate)/polyaniline (PMMA/PANI) blend nanofibres were prepared by electrospinning and dip-coating polymerisation techniques. The semiconducting behaviour of PMMA/PANI blend was found to be highly sensitive for toxic gases like $\mathrm{NH}_{3}$ and $\mathrm{HCl}$ at room temperature suggesting the PMMA/PANI blends as a potential material for effective gas sensing in the environmental monitoring safety systems, chemical industry, automotive industry and medical application areas. Fourier transform infrared (FTIR) spectra clearly show the characteristic peaks indicating the presence of quinoid and benzenoid rings of PANI confirming the formation of PMMA/ PANI blend. Clusters of PANI on the uniform fibres of PMMA can be seen in the SEM images. Good thermal stability of PMMA/PANI nanofibres showed to be highly sensitive with fast response and recovery on exposure to $\mathrm{NH}_{3}$ and $\mathrm{HCl}$ gases. The phenomenon of increase in sensitivity with the increase in concentration of $\mathrm{NH}_{3}$ and $\mathrm{HCl}$ gases was found to be adsorption dominated indicating that the PMMA/PANI blend nanofibres are more sensitive to the surrounding due to their increased porosity and high aspect ratio. The sensing mechanism of PMMA/PANI blend nanofibres on account of more protonation and de-protonation due to exposing towards $\mathrm{HCl}$ and $\mathrm{NH}_{3}$ gases respectively is systematically explained in the present investigation.
\end{abstract}

Keywords: Polyaniline, poly(methyl methacrylate), nanofibres, electrospinning, gas sensing 


\section{INTRODUCTION}

Toxic gases are a major concern for the environmentalists due to the possibility of accidental leakage of gases in chemical storage. Due to increased human safety concerns and environmental monitoring requirements, there is a considerable attention in recent years on sensors based on advanced materials for toxic gases. ${ }^{1,2}$ $\mathrm{NH}_{3}$ and $\mathrm{HCl}$ gases are not only hazardous to humans but also harm the aquatic life on a large scale since both gases are soluble in water. The widespread use of ammonia in farms and industrial locations makes humans vulnerable to its exposure. Ammonia gas forms the very caustic ammonium hydroxide in contact with the available moisture in skin, eyes, oral cavity and respiratory tract. Similarly, the colourless, with a pungent odour of $\mathrm{HCl}$ gas forms hydrochloric acid on contact with the moisture. Exposure to $\mathrm{HCl}$ gas may occur by inhalation, ingestion, or eye or skin contact. Skin contact causes burns and ulcers in case of exposure to higher concentrations of $\mathrm{HCl}$ gas.

In order to save human and aquatic life from the unwanted harmful effects of these toxic gases, it is necessary to detect them at possible sites of more than warranted exposure at room temperature. Higher levels of $\mathrm{HCl}$ and ammonia gases are easily detected since both gases have pungent and penetrating odour. However, it may be extremely necessary to detect and quantify the low concentrations of these gases in specific application areas since the human nose fails at such lower concentrations. For example, in a chemical industry where several processes may be carried out at temperatures as high as $500^{\circ} \mathrm{C}$, leakage alarms are required to be installed to detect ammonia leakages in the range of $20 \mathrm{ppm}$ to less than $1000 \mathrm{ppm}$ within minutes of leakage. At present, much of the research work has been carried out for the detection of ammonia gases. ${ }^{3,4}$ Several gas sensors have been developed in the past suitable for the specific application purpose. ${ }^{5}$ A gas sensor is a chemical sensor that transforms chemical information such as the concentration of a specific gas component into a useful analytical signal. As compared to the commercially available gas sensors mostly based on metal oxides and operated at high temperatures, the sensors fabricated from conducting polymers have added advantages. ${ }^{6-8}$ They have relatively high sensitivity and short response time, which makes them attractive commercially, especially when these features are ensured at or near room temperature. Since the nanostructure materials prepared in the form of thin films have large surface area to volume ratio, a porous surface morphology which allows for larger adsorption of gas molecules, nanoscale conducting polymers may be the right candidates for sensing application with high sensitivity, less response time at room temperature. The nanofibres (1D) of conducting polymers have superior mechanical characteristics such as higher stiffness and tensile strength as well as flexibility in surface functionalities. ${ }^{9}$ Therefore these materials are most suitable for gas as well as bio-chemical 
sensing as compared to thin films made of nanoparticle (0D) or nanofilm (2D) or nanocrystal (3D) materials.

In recent years, a number of processing techniques has been used to prepare conducting polymer nanofibres such as hard templates, soft templates, phase separation, self-assembly, seeding, interfacial polymerisation, rapidly mixing and electrospinning. ${ }^{10,11}$ Although there are various methods to fabricate nanofibres of the conducting polymers, electrospinning is the most simple, cost effective, convenient, and versatile process to produce fibres with a very large aspect ratio in mass scale. ${ }^{12}$ Polyaniline is one of the most extensively studied conducting polymers because it can be easily synthesised and exhibits moderately high conductivity on doping. Moreover, electronic structure and electrical properties of polyaniline can be reversibly controlled by oxidation as well as protonation.

The polymer chains of conducting polyaniline are short to be electrospun into long fine fibres. Therefore, another polymer with sufficiently long chain length is required to blend with polyaniline for electrospinning. Polymers such as polyethylene (PEO), polymethyl methacrylate (PMMA), polyvinyl alcohol (PVA), polyvinyl pyrrolidine (PVP), polyacrylonytrile (PAN), polystyrene (PS), etc., can be used not only as carrier polymer for electrospinning to get sufficient viscosity of the polymer solution. Blends of conducting and nonconducting polymers are prepared to extract the desirable properties of the individual constituents which may be otherwise absent in them. The sensing materials used in sensors largely influence the performance parameters such as stability, response time, reliability, sensitivity, performance temperature, lifetime, accuracy, etc. Many kinds of materials such as metal oxides, semiconductors, polymers, carbon, graphite and organic/inorganic composites and blends have been used as sensing materials to detect the targeted gases using several sensing principles and techniques. ${ }^{13,14}$

It would be noteworthy here that the sensitivity of chemical gas sensors is strongly determined by the specific surface area of sensing material exposed to the gases. A higher specific surface of the sensing material will lead to higher sensitivity of the sensor. The nanofibres not only offer higher surface area to volume ratio but also inherent large aspect ratio which makes it a quick sensor as compared to the thin films. A very low concentration of chemical vapours is sufficient to change the electrical properties of the sensing elements made of nanofibres.

In the present study, PMMA/PANI blend nanofibres have been synthesised through electrospinning and dip-coating polymerisation. The novelties of this work are the blend nanofibre preparation and its application for toxic gases. The coating of conducting PANI on PMMA nanofibres ensures a change in the conductivity on exposure to $\mathrm{HCl}$ as well as ammonia gas thus enabling the use of prepared blend 
as a chemical gas sensor. A decrease in the conduction (or increase in resistance) confirms the presence of $\mathrm{NH}_{3}$ whereas an increase in the conduction (or decrease in the resistance) confirms the presence of $\mathrm{HCl}$. Keeping in view the fact that exposure to high $\mathrm{HCl}$ and $\mathrm{NH}_{3}$ concentration is dangerous for human beings, PMMA/PANI blend nanofibres were explored for the sensing of $\mathrm{HCl}$ and $\mathrm{NH}_{3}$ gas at room temperature.

\section{EXPERIMENTAL}

\subsection{Materials}

Aniline $\left(\mathrm{C}_{6} \mathrm{H}_{5} \mathrm{NH}_{2}\right.$, mol.wt. $93.13 \mathrm{~g} \mathrm{~mol}^{-1}$, purity $\left.99 \%\right)$ was obtained from Fisher Scientific. Ammonium peroxydisulphate (APS $\left(\mathrm{NH}_{4}\right)_{2} \mathrm{~S}_{2} \mathrm{O}_{8}$, mol.wt. $228.19 \mathrm{~g} \mathrm{~mol}^{-1}$, purity $99 \%$ ) and poly (methyl methacrylate) (PMMA $\left(\mathrm{C}_{5} \mathrm{O}_{2} \mathrm{H}_{8}\right)_{\mathrm{n}}$, mol.wt. 350,000) were procured from Sigma Aldrich. Hydrochloric acid $(\mathrm{HCl}$, mol.wt. $36.46 \mathrm{~g} \mathrm{~mol}^{-1}$ ) and N, N-Dimethyl Formamide (DMF, $\mathrm{C}_{3} \mathrm{H}_{7} \mathrm{ON}$, mol.wt. $73.09 \mathrm{~g} \mathrm{~mol}^{-1}$, purity $99.5 \%$ ) were procured from Hi-media. All chemicals were of analytical grade and used as received except aniline which was purified and kept below $5^{\circ} \mathrm{C}$ before being used. Deionised water was used in all syntheses.

\subsection{Synthesis of PMMA/PANI Blend Nanofibres}

Firstly, 2.2 g PMMA was dissolved in $15 \mathrm{ml}$ DMF and magnetically stirred for $1 \mathrm{~h}$ to get homogeneous solution. PMMA solution was then loaded into a $5 \mathrm{ml}$ disposable plastic syringe with the metallic needle of $0.5 \mathrm{~mm}$ diameter for electrospinning. During the electrospinning process at room temperature in air, the solution was fed to the tip using a computer-controlled syringe pump at a flow rate of $0.2 \mathrm{ml} \mathrm{h}^{-1}$. A positive voltage of $20 \mathrm{kV}$ was applied to the needle of the syringe containing solution and the metallic plate wrapped with aluminium foil was grounded and kept at a distance of $15 \mathrm{~cm}$ from the needle of the syringe. The electrospun nanofibres were collected on the conducting foil (aluminium). After electrospinning, the nonwoven membrane of PMMA nanofibres was dried at $60^{\circ} \mathrm{C} .{ }^{15}$ Further, as-prepared PMMA nanofibres were used for coating polyaniline to form PMMA/PANI blend nanofibres by using dip-coating in-situ chemical oxidative polymerisation process. ${ }^{16,17}$

In the typical process of polymerisation, $0.4 \mathrm{M}$ aniline solution was prepared with $50 \mathrm{ml}$ of $1 \mathrm{M} \mathrm{HCl}$ in double distilled water. A solution of $0.45 \mathrm{M}$ ammonium peroxydisulphate (APS) was prepared with $50 \mathrm{ml}$ of $1 \mathrm{M} \mathrm{HCl}$ in double distilled water and mixed to aniline solution drop wise at $5^{\circ} \mathrm{C}$ while stirring for $5 \mathrm{~h}$. Asprepared PMMA nanofibres were inserted into the solution during polymerisation 
using dip-coating technique. PANI grew on PMMA nanofibres due to chemical oxidation of aniline and the solution turned dark green. PMMA/PANI nanofibres were clearly washed with double distilled water and dried at $80^{\circ} \mathrm{C}$ in vacuum oven. The schematic of preparation and application of PMMA/PANI blend nanofibres is shown in Scheme 1.

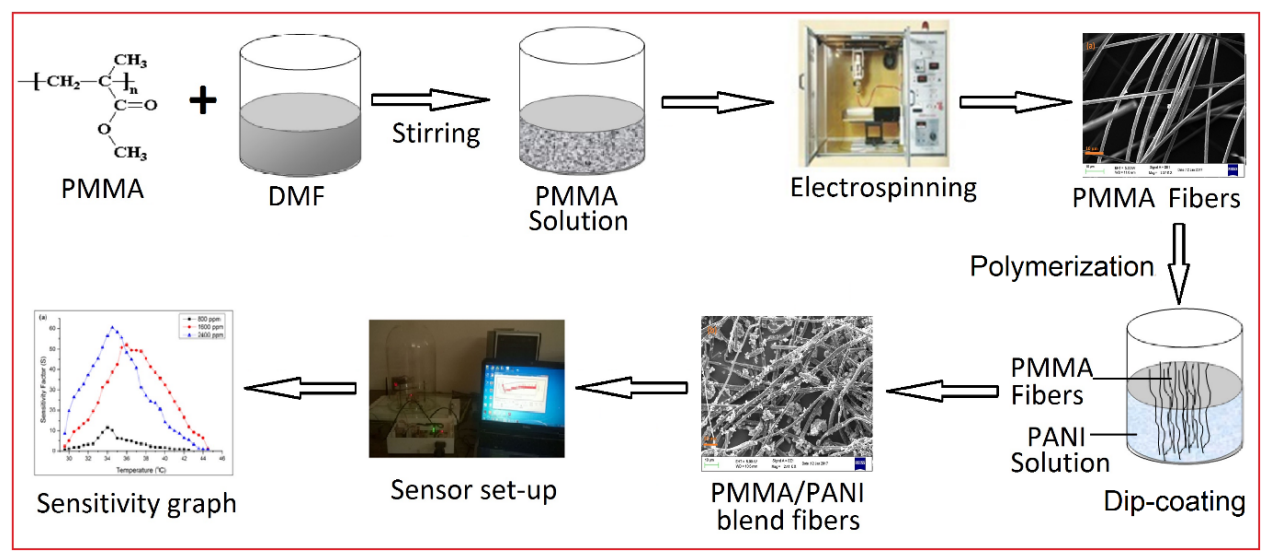

Scheme 1: Schematic of preparation and sensing application of nanofibrous PMMA/PANI blend nanofibres.

\subsection{Instrumental Analysis}

Pure PMMA and PMMA/PANI blend fibres were characterised by scanning electron microscopy (SEM), Fourier transform infrared spectroscopy (FTIR) and thermal gravimetric-differential thermo-gravimetric analysis (TGA-DTG) techniques. SEM images of were recorded on Carl Zeiss EVO-18 scanning electron microscope. FTIR spectra were recorded on Bruker Alpha Spectrophotometer in the $4000-500 \mathrm{~cm}^{-1}$ range. TGA-DTG was done on Hitachi STA7200 Thermal Analysis System.

\section{RESULTS AND DISCUSSION}

\subsection{SEM}

SEM images of pure PMMA and PMMA/PANI blend nanofibres are shown in Figure 1. Pure PMMA exhibits long and uniformly thin nanofibres compared to that of PMMA/PANI blend nanofibres. White coloured clusters of PANI can be seen coated on the PMMA nanofibres confirming the formation of PMMA/PANI with increased in diameter compared to that of pure PMMA. 


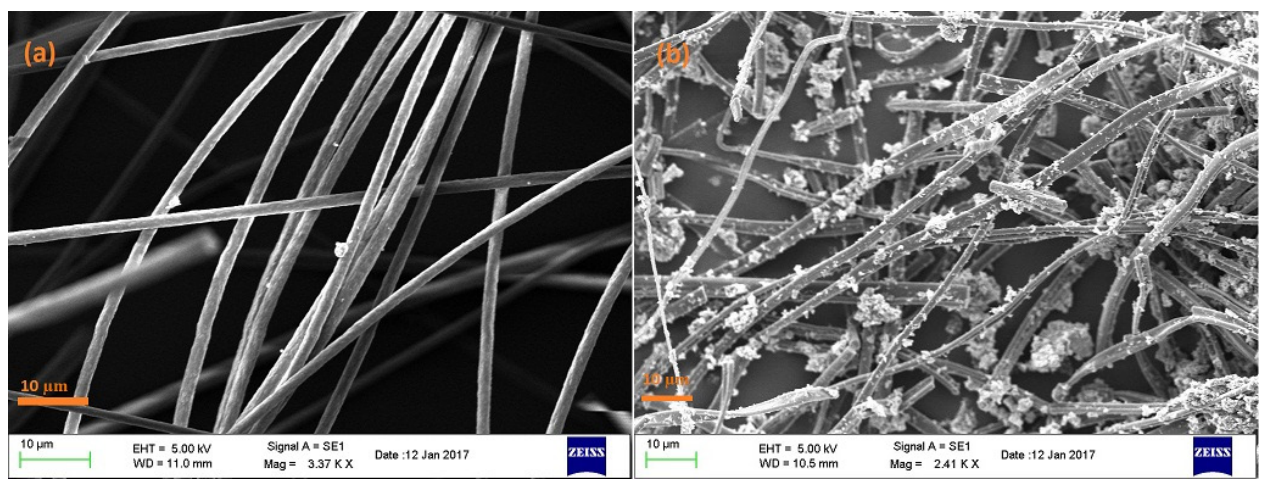

Figure 1: SEM images of PMMA nanofibres and PMMA/PANI blend nanofibres.

\subsection{FTIR Spectroscopy}

FTIR spectra for PMMA and PMMA/PANI blend nanofibres are shown in Figure 2. The peak at $2977.29 \mathrm{~cm}^{-1}$ corresponds to the $\mathrm{C}-\mathrm{H}$ stretching vibrations. ${ }^{18,19}$ The intense peak at $1725.90 \mathrm{~cm}^{-1}$ is attributed to the $\mathrm{C}=\mathrm{O}$ stretching vibrations. The asymmetrical bending vibrations of C-O-C are located at 1241.11 $\mathrm{cm}^{-1}$ and $1146.46 \mathrm{~cm}^{-1} \cdot 20,21$ In the FTIR of the blend, a peak at $1699.87 \mathrm{~cm}^{-1}$ is attributed to the $\mathrm{COO}$ stretching vibrations confirming the presence of carboxyl group. ${ }^{22}$ The peaks due to the $\mathrm{C}=\mathrm{C}$ stretching of the quinoid ring and the benzenoid ring can be seen located at $1615 \mathrm{~cm}^{-1}$ and $1458.43 \mathrm{~cm}^{-1}$ respectively, confirming the existence of PANI in the blend..$^{23}$ The peak due to the bending of $\mathrm{C}-\mathrm{H}$ of aromatic ring is observed at $1136.95 \mathrm{~cm}^{-1} .{ }^{24}$ Increase in the intensity of the peaks in the FTIR of PMMA/PANI blend can be seen at $751 \mathrm{~cm}^{-1}, 3738 \mathrm{~cm}^{-1}$ and $3860 \mathrm{~cm}^{-1}$ which are obtained due to the vibrations of polymer chains.

\subsection{TGA-DTG Analysis}

TGA and DTG curves of pure PMMA and PMMA/PANI blend nanofibres are shown in Figure 3. The three stages of weight loss in PMMA can be seen at $140^{\circ} \mathrm{C}-250^{\circ} \mathrm{C}, 270^{\circ} \mathrm{C}-325^{\circ} \mathrm{C}$ and $325^{\circ} \mathrm{C}-410^{\circ} \mathrm{C} .{ }^{25}$ The lower weight loss in the first two degradation steps may be attributed to the evaporation of the residual solvent and the splitting of small molecules. The higher loss in weight in the third degradation step indicates the structural decomposition of bonds due to heat at higher temperature. The high intensity peak in the DTG of pure PMMA may be attributed to the corresponding higher weight loss in the third degradation step. ${ }^{26}$ The degradation of the PMMA-PANI also takes place in three steps. Increased thermal stability of PMMA-PANI blend can be attributed to the shift in the third degradation step of PMMA-PANI towards higher temperature. ${ }^{27}$ 


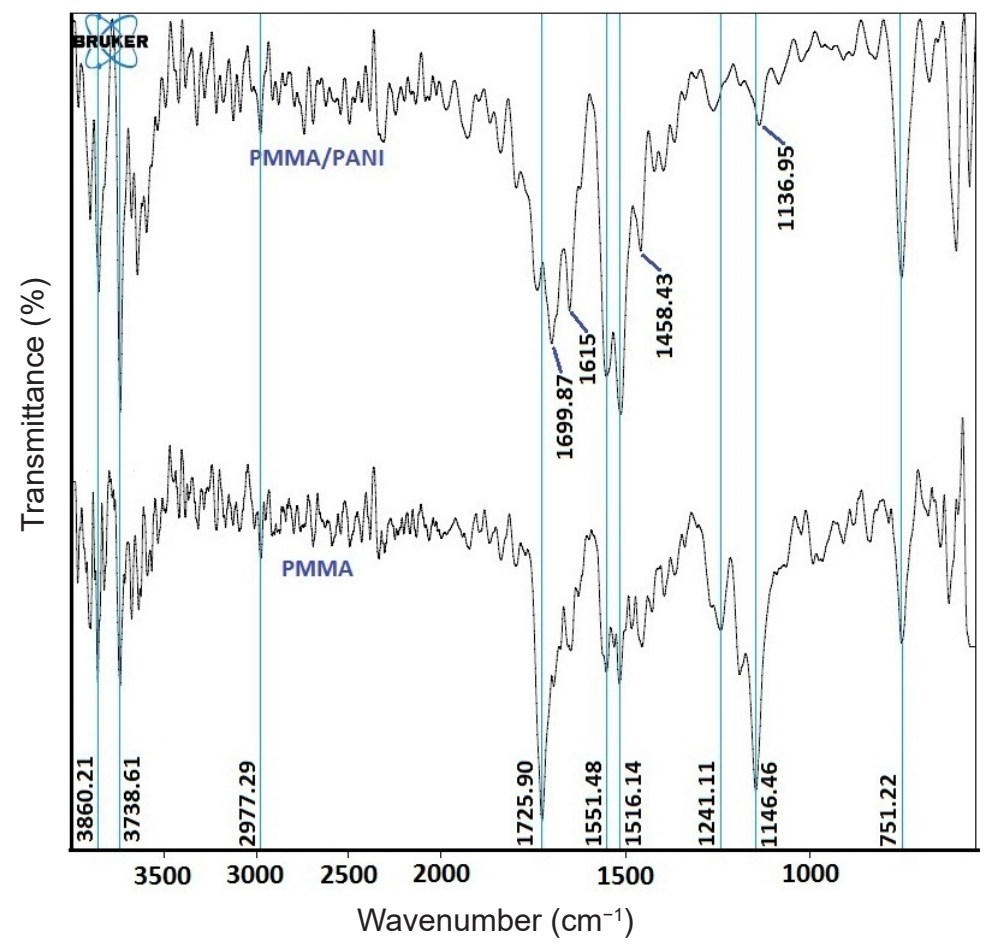

Figure 2: FTIR spectra of PMMA and PMMA/PANI blend nanofibres.

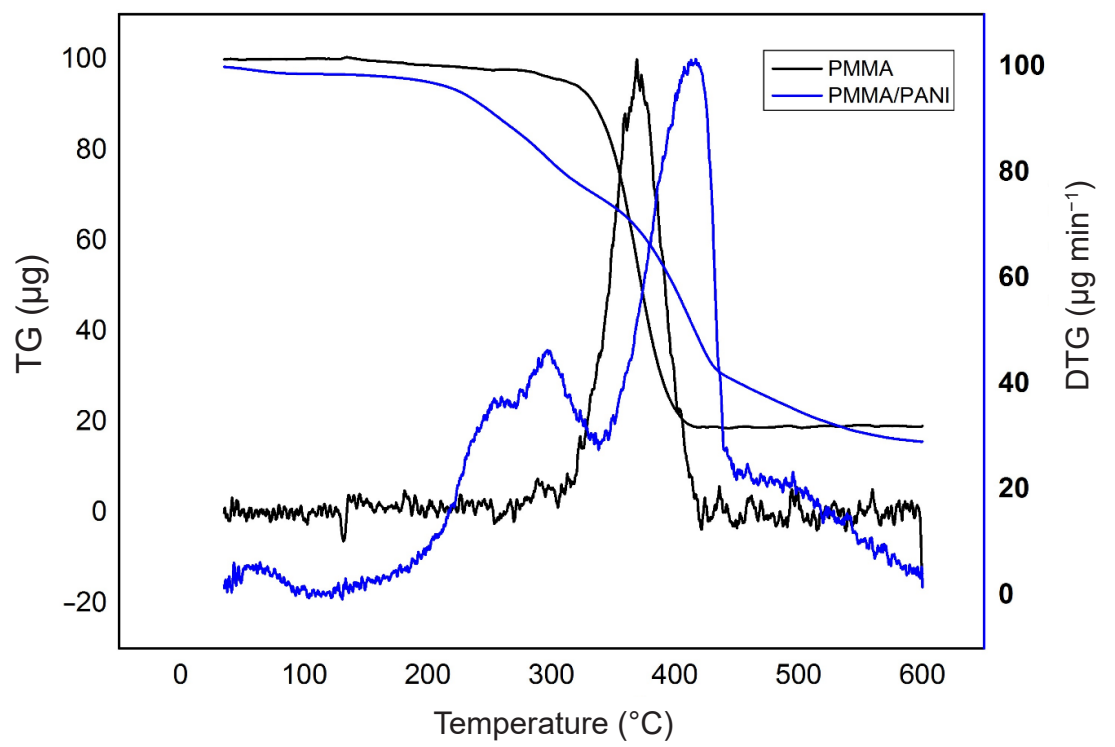

Figure 3: TGA-DTG curves of PMMA and PMMA/PANI blend nanofibres. 


\section{4 $\mathrm{HCl}$ and $\mathrm{NH}_{3}$ Gas Sensing}

Gas sensors are the detectors which sense or detect a particular gas (analyte) and convert the information into a useful analytical signal, mostly electrical. ${ }^{28-30}$ Although an ideal gas sensor must have all ideal characteristics such as high sensitivity, good selectivity, low detection limit, good linearity, small hysteresis and response time, and long life cycle, efforts can be made to approach only some of these ideal characteristics and disregarding the others since the real applications usually do not require all perfect characteristics at once. There are several papers which report the use of different organic polymers as well as metal oxide-based polymer nanocomposites as efficient gas sensors for ammonia as well as $\mathrm{HCl}$ gases. ${ }^{31-34}$ The synthesised PMMA/PANI blend nanofibres were used as the receptor for analyte gas molecules. Exposure of the fabricated PMMA/PANI sensor to $\mathrm{HCl}$ gas showed decrease in the resistance with increasing temperature whereas an increase in the resistance with increasing temperature was observed for ammonia gas.

The PANI layer in the blend acts as the active sensing layer and shows changes in the resistivity on adsorption of the analyte gas molecules. The sensitivity of PMMA/ PANI sensor calculated for both $\mathrm{HCl}$ and $\mathrm{NH}_{3}$ gas for different concentrations are shown in Figures 4 and 5, respectively. It was observed that the sensitivity of the sensor increases for higher concentration of $\mathrm{HCl}$ gas. It is worth mentioning that the sensitivity is highest at near room temperature although the working temperature slightly differs with concentrations.

Also, the sensitivity of the sensor increases with increasing concentration of ammonia gas, though the highest sensitivity here is lower than the sensitivity for the corresponding $\mathrm{HCl}$ concentration. The sensing mechanism is found to be governed by protonation and deprotonation phenomena. The resistivity of the blend increases in the presence of ammonia gas due to the reduction or undoping of charge carriers by adsorption of ammonia molecules on the surface of blend. The sensitivity factor was found to be $11.53,52.10$ and 60.47 for $800 \mathrm{ppm}$, $1600 \mathrm{ppm}$ and $2400 \mathrm{ppm}$ of $\mathrm{HCl}$ at temperatures of $34^{\circ} \mathrm{C}, 36^{\circ} \mathrm{C}$ and $34.5^{\circ} \mathrm{C}$, respectively. For ammonia gas, the sensitivity factor was obtained as $11.29,19.38$ and 27.84 for $800 \mathrm{ppm}, 1600 \mathrm{ppm}$ and $2400 \mathrm{ppm}$ at temperatures of $36.5^{\circ} \mathrm{C}, 39^{\circ} \mathrm{C}$ and $42^{\circ} \mathrm{C}$ respectively. A plot of response $\left(\mathrm{R}_{\mathrm{g}} / \mathrm{R}_{\mathrm{a}}\right)$ and recovery of the sensor for the analyte gases $\mathrm{HCl}$ and $\mathrm{NH}_{3}$ with respect to time is shown in Figures 6 and 7 , respectively. It can be seen that the response of the sensor increases for increasing concentration of $\mathrm{HCl}$ as well as $\mathrm{NH}_{3}$ gas with the highest response for $2400 \mathrm{ppm}$ of ammonia gas. Figure 8 depicts the plot of sensitivity versus concentration for the values of factor $\mathrm{S}$ for different concentrations obtained from the Figures 4 
and 5 at room temperature. A plot of response versus concentration of the two gases is shown in Figure 9.

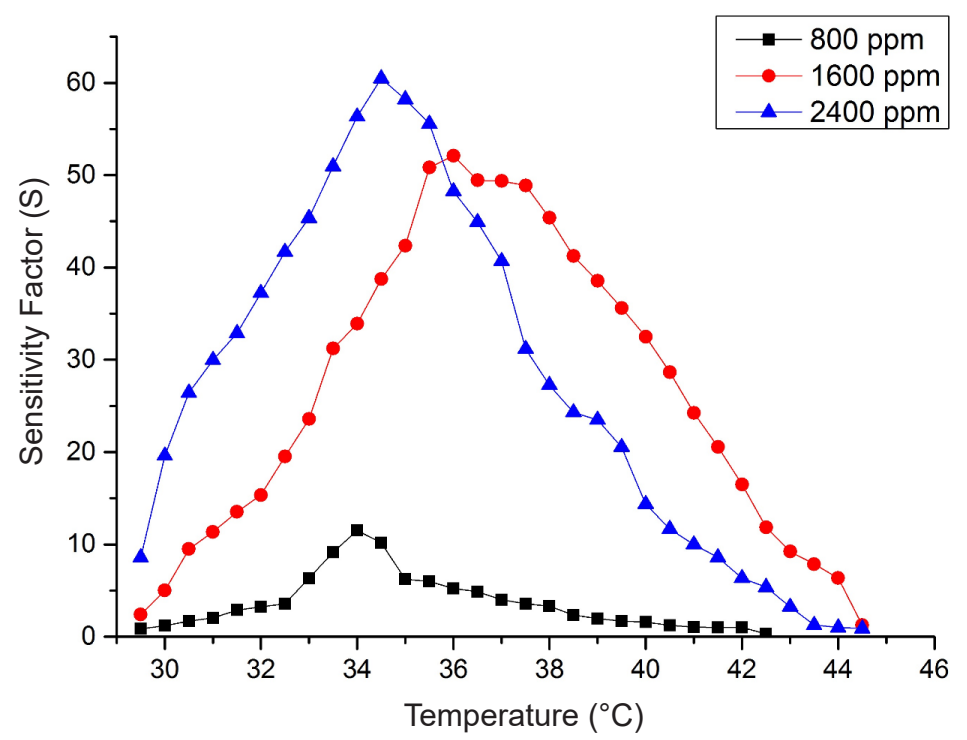

Figure 4: Sensitivity of the PMMA/PANI blend sensor for $\mathrm{HCl}$ gas at different concentrations.

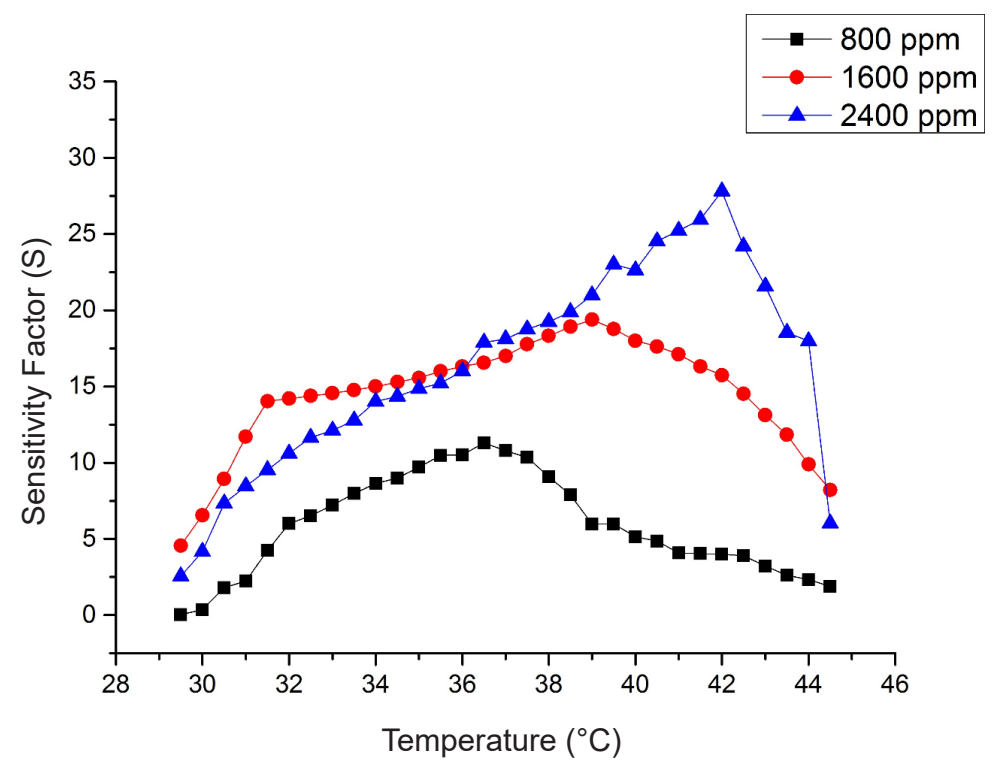

Figure 5: Sensitivity of the PMMA/PANI blend sensor for $\mathrm{NH}_{3}$ gas at different concentrations. 


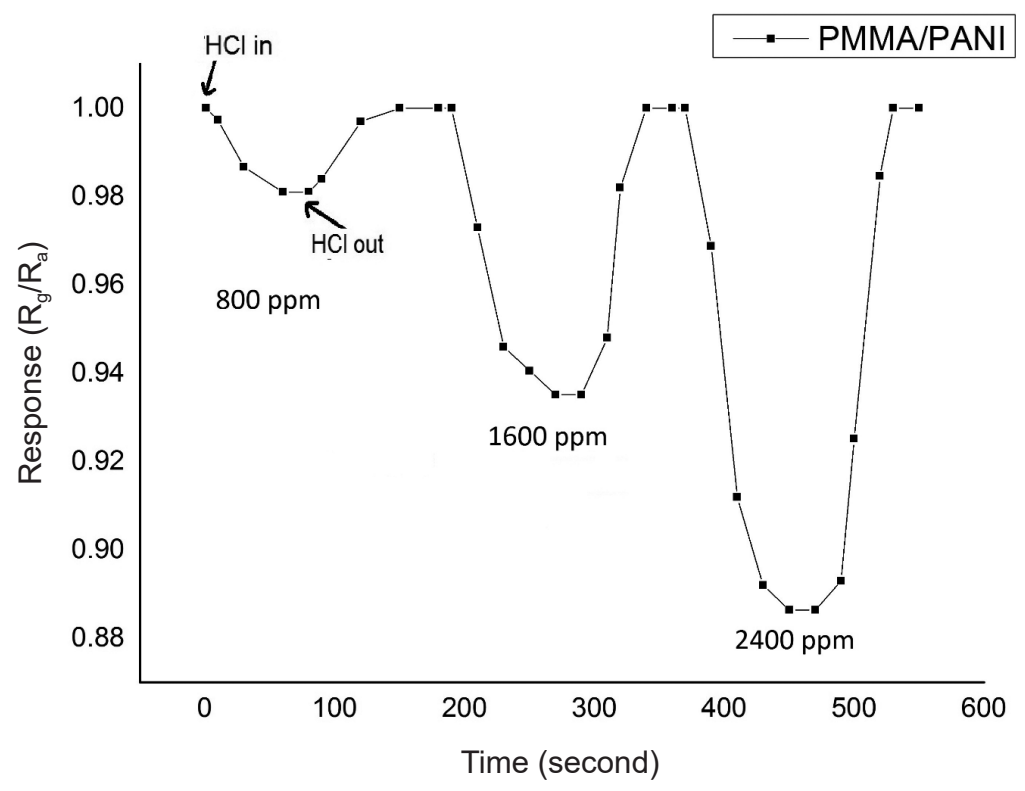

Figure 6: Response and recovery of PMMA/PANI blend sensor for $\mathrm{HCl}$ gas at different concentrations.

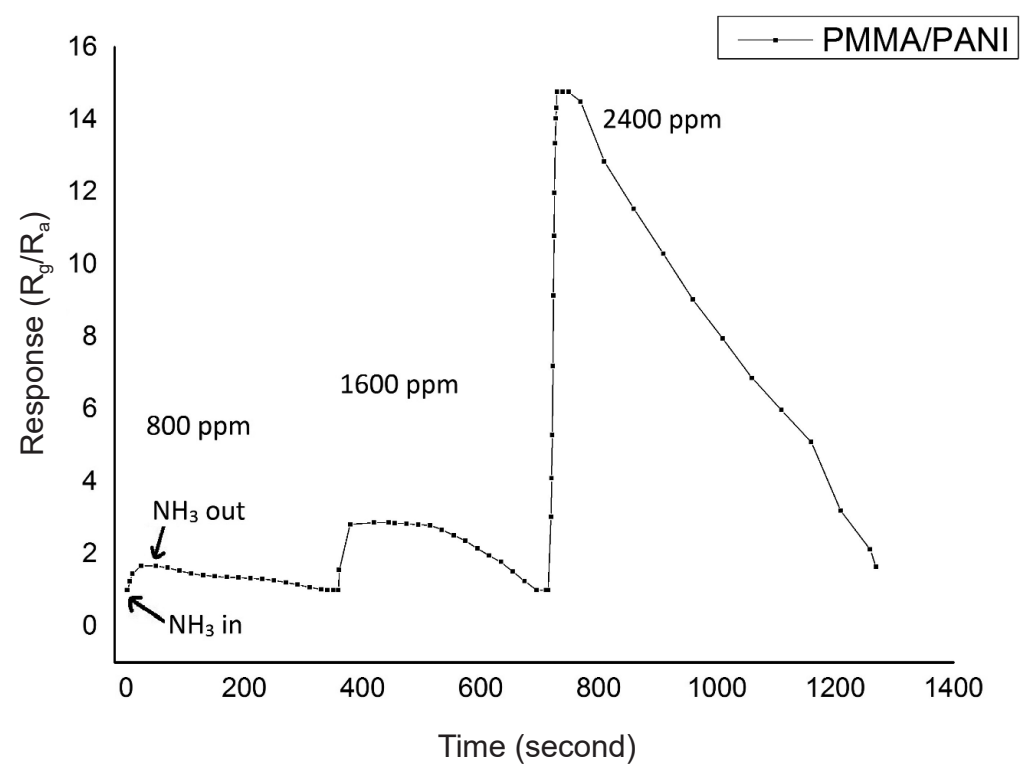

Figure 7: Response and recovery of PMMA/PANI blend sensor for $\mathrm{NH}_{3}$ gas at different concentrations. 
The nanofibrous gas sensor fabricated from the PMMA/PANI blend in the present work is a good sensor since it is highly sensitive for $\mathrm{HCl}$ as well as $\mathrm{NH}_{3}$ gases and has operating temperature below $37^{\circ} \mathrm{C}$ for $\mathrm{HCl}$ gas and $42^{\circ} \mathrm{C}$ for ammonia gas, much closer to room temperature. The nanofibrous morphology of the sensor allows for the quick diffusion of the gas molecules enabling the sensor to show quick response. Tables 1 and 2 show the comparison of the sensitivity, response time, recovery time and operating temperature of as-synthesised PMMA/PANI blend nanofibres for $\mathrm{NH}_{3}$ and $\mathrm{HCl}$ gases respectively with that of the work for other materials such as camphor sulfonic acid doped $\mathrm{PANI} / \mathrm{SnO}_{2}$, polyaniline/ titania $\left(\mathrm{PANI} / \mathrm{TiO}_{2}\right)$, polyaniline particles/reduced graphene oxide-polyaniline fibres (PPANI/rGO-FPANI), polyaniline-single walled carbon nanotubes (PANISWNTs), polyaniline/zinc oxide (PANI/ZnO), tetracationic porphyrin/titania (TMPyP/TiO 2 ), meso-tetramesitylporphyrin (MTMP), when used for gas sensing reported in literature. ${ }^{35-41}$ There are many composite materials used for $\mathrm{NH}_{3}$ gas sensing, but very few materials are used for $\mathrm{HCl}$ gas sensing. Thus, PMMA/PANI blend nanofibres proves to be a good sensor for $\mathrm{HCl}$ as well as $\mathrm{NH}_{3}$ gases closed to room temperature compared to other materials reported not used for both the gases sensing.

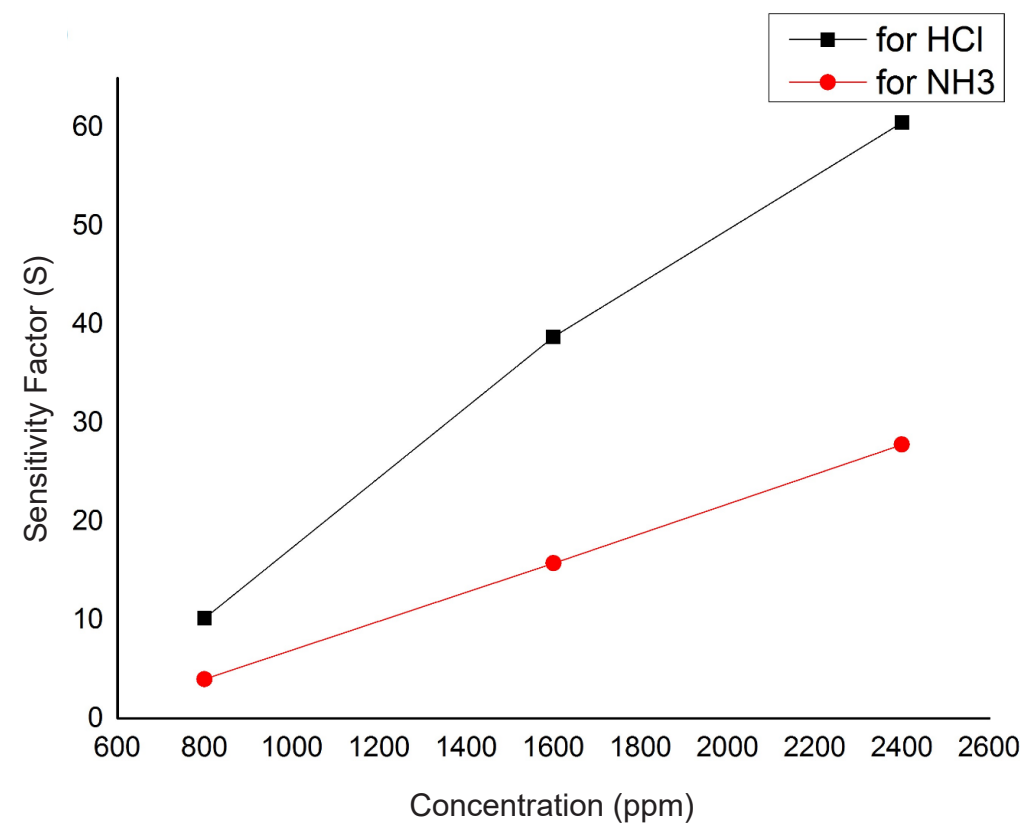

Figure 8: A plot of sensitivity versus concentration of PMMA/PANI blend sensor for $\mathrm{HCl}$ and $\mathrm{NH}_{3}$ gas. 


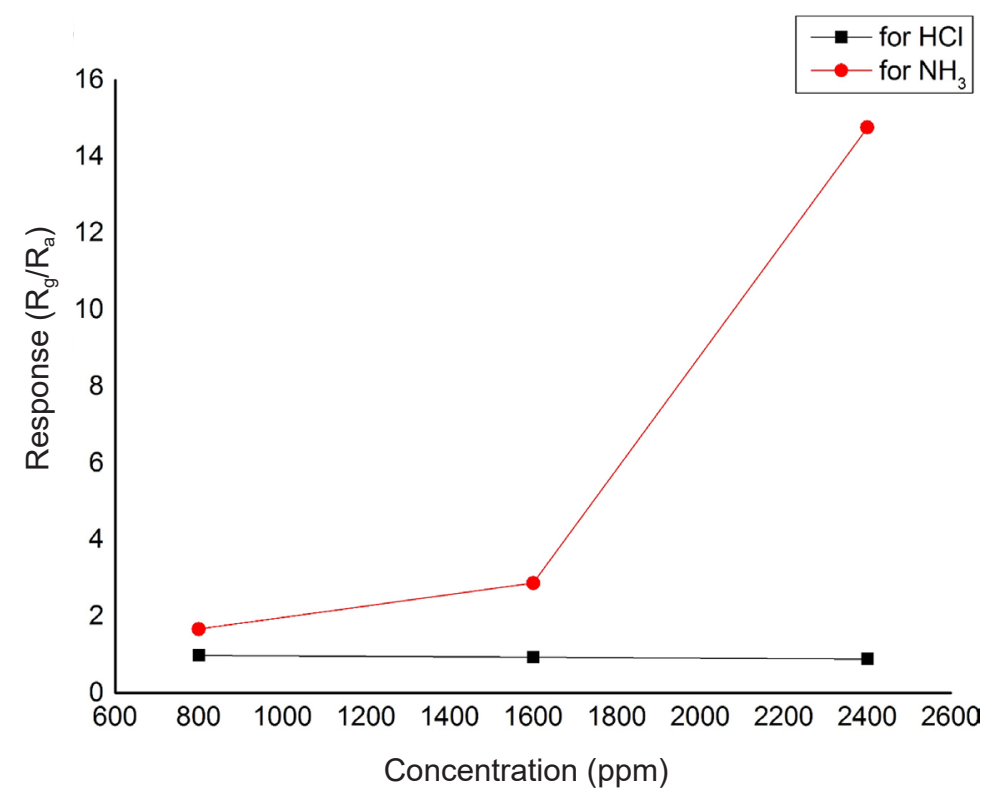

Figure 9: A plot of response versus concentration of PMMA/PANI blend sensor for $\mathrm{HCl}$ and NH3 gas.

Table 1: Comparison of the sensitivity, response time, recovery time and operating temperature of as-synthesised PMMA/PANI blend nanofibres for $\mathrm{NH}_{3}$.

\begin{tabular}{lccccc}
\hline \multicolumn{1}{c}{ Sensing materials } & $\begin{array}{c}\text { Operating } \\
\text { temperature }\left({ }^{\circ} \mathrm{C}\right)\end{array}$ & $\begin{array}{c}\text { Sensitivity } \\
(\mathrm{S} \%)\end{array}$ & $\begin{array}{c}\text { Response } \\
\text { time }(\mathrm{s})\end{array}$ & $\begin{array}{c}\text { Recovery } \\
\text { time }(\mathrm{s})\end{array}$ & Reference \\
\hline PMMA/PANI & 42 & 27.8 & 22 & 400 & Present work \\
CSA doped PANI/SnO ${ }_{2}$ & 30 & 0.91 & 46 & 3245 & Khusp et al. ${ }^{35}$ \\
PANI/TiO & & 12 & 72 & - & Pawar et al. $^{36}$ \\
PPANI/rGO-FPANI & 40 & 5 & 36 & 18 & Gua et al. ${ }^{37}$ \\
PANI-SWNT & $\mathrm{RT}$ & 5.8 & 450 & - & Lim et al. ${ }^{38}$ \\
PANI-ZnO & 45 & 4.6 & 153 & 135 & Patil et al. $^{39}$ \\
\hline
\end{tabular}

Table 2: Comparison of the sensitivity, response time, recovery time and operating temperature of as-synthesised PMMA/PANI blend nanofibres for $\mathrm{HCl}$.

\begin{tabular}{lccccl}
\hline Sensing materials & $\begin{array}{c}\text { Operating } \\
\text { temperature }\left({ }^{\circ} \mathrm{C}\right)\end{array}$ & $\begin{array}{c}\text { Sensitivity } \\
(\mathrm{S} \%)\end{array}$ & $\begin{array}{c}\text { Response } \\
\text { time }(\mathrm{s})\end{array}$ & $\begin{array}{c}\text { Recovery } \\
\text { time }(\mathrm{s})\end{array}$ & Reference \\
\hline PMMA/PANI & 34.5 & 60.4 & 60 & 90 & Present work \\
$(\mathrm{TMPyP}) / \mathrm{TiO}_{2}$ & 80 & 0.91 & 50 & 300 & Kaushik et al. ${ }^{40}$ \\
$\mathrm{MTMP}$ & 557 & 12 & 600 & 900 & Kalimuthu et al. $^{41}$ \\
\hline
\end{tabular}




\subsection{Sensing Mechanism}

The sensing mechanism that takes place on the molecular level due to the adsorption of $\mathrm{HCl}$ and $\mathrm{NH}_{3}$ gas on the PANI layer is depicted in Figures 10 and 11, respectively. Since $\mathrm{HCl}$ is used as a dopant during polymerisation in this work, PANI is obtained in the form of emeraldine salt. When exposed to $\mathrm{HCl}$ gas during sensing, the $\mathrm{HCl}$ molecule donates $\mathrm{H}^{+}$ions to the PANI chain, thus increasing the number of positively charged carriers in the material. The process is termed as protonation and gives bipolarons due to excess doping of PANI and results in decrease in the electrical resistivity of the sensor. With the increasing concentration of the analyte $\mathrm{HCl}$ gas, the sensitivity is increased which is attributed to the diffusion of more $\mathrm{HCl}$ molecules into the fibre at higher concentration. On the other hand, when the sensor is exposed to the ammonia gas, deprotonation takes place. $\mathrm{NH}_{3}$ molecules of gas take up the hydrogen atom from the PANI chain and form $\mathrm{NH}_{4}^{+}$ammonium ions. The emeraldine salt form of the PANI thus changes into the emeraldine base form with decrease in the number of carriers. This leads to the decrease in the number of polarons and the electrical resistivity of the sensor increases. Here too the sensitivity is found to increase with the increasing concentration of the $\mathrm{NH}_{3}$ gas which indicates that more $\mathrm{NH}_{3}$ molecules diffuse into the fibre at higher concentration.

The response and recovery time are defined as the time to reach $90 \%$ of the resistance change during exposure and on removal of gas respectively. The response and recovery time of the PMMA/PANI blend nanofibres based sensor on exposure to different $\mathrm{HCl}$ concentrations was found to be almost the same indicating adsorption and desorption of $\mathrm{HCl}$ molecules in the blend takes almost same time on exposure to the gas and removal of gas respectively. The lower response time of the PMMA/PANI blend for $\mathrm{NH}_{3}$ gas indicates the faster diffusion of the gas molecules into the fibre immediately upon exposure to the gas. On the other hand, the recovery time (reversibility) of the sensor was found to be poor. This may be attributed to the difficulty of the adsorbed $\mathrm{NH}_{3}$ molecules to desorb from the fibre. The response and recovery rate may be improved by fabricating a nanofibrous sheet of aligned nanofibres of PMMA which will further increase the available surface area for PANI coating during dip-coating polymerisation, thereby increasing the possibility of quick response and recovery. Attempts can be made to spin the PMMA nanofibres of reduced diameters by optimising the affecting parameters. This will again result in increased specific surface area leading to quicker gas response and reversibility. 

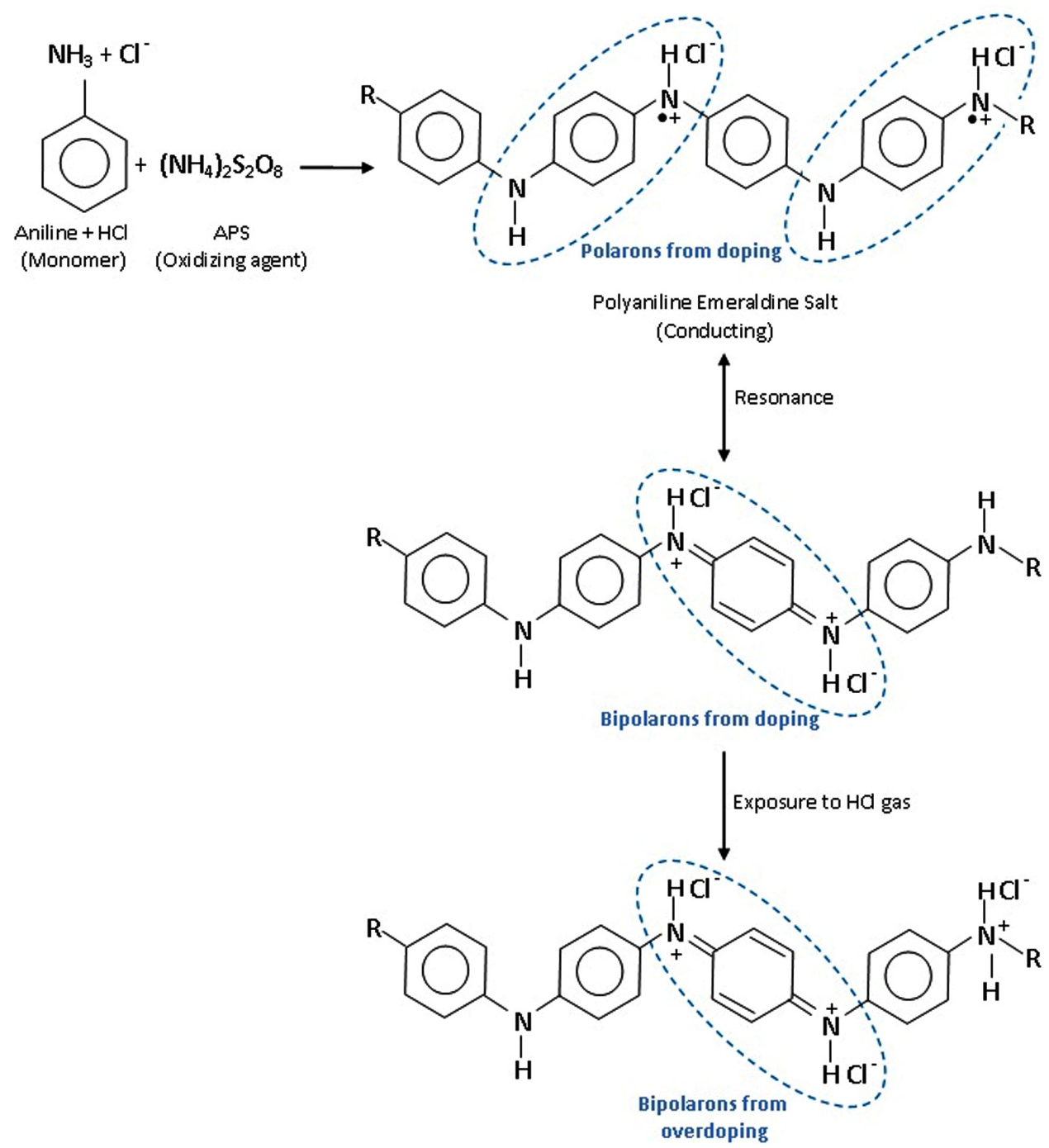

Figure 10: Sensing mechanism of the PMMA/PANI blend on exposure to $\mathrm{HCl}$ gas. 


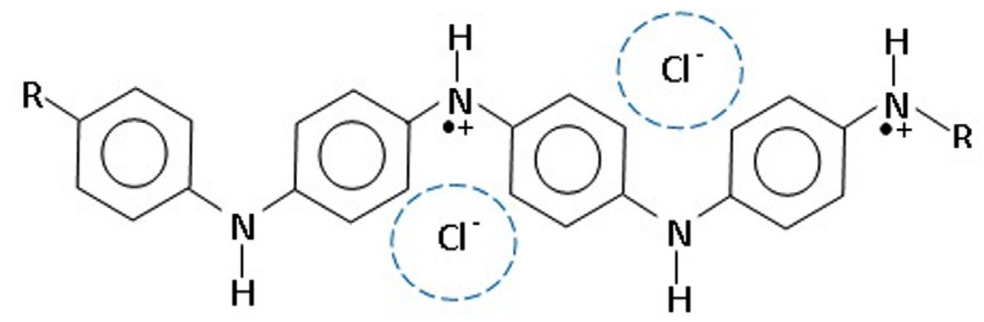

Polyaniline Emeral dine Salt

(Conducting)

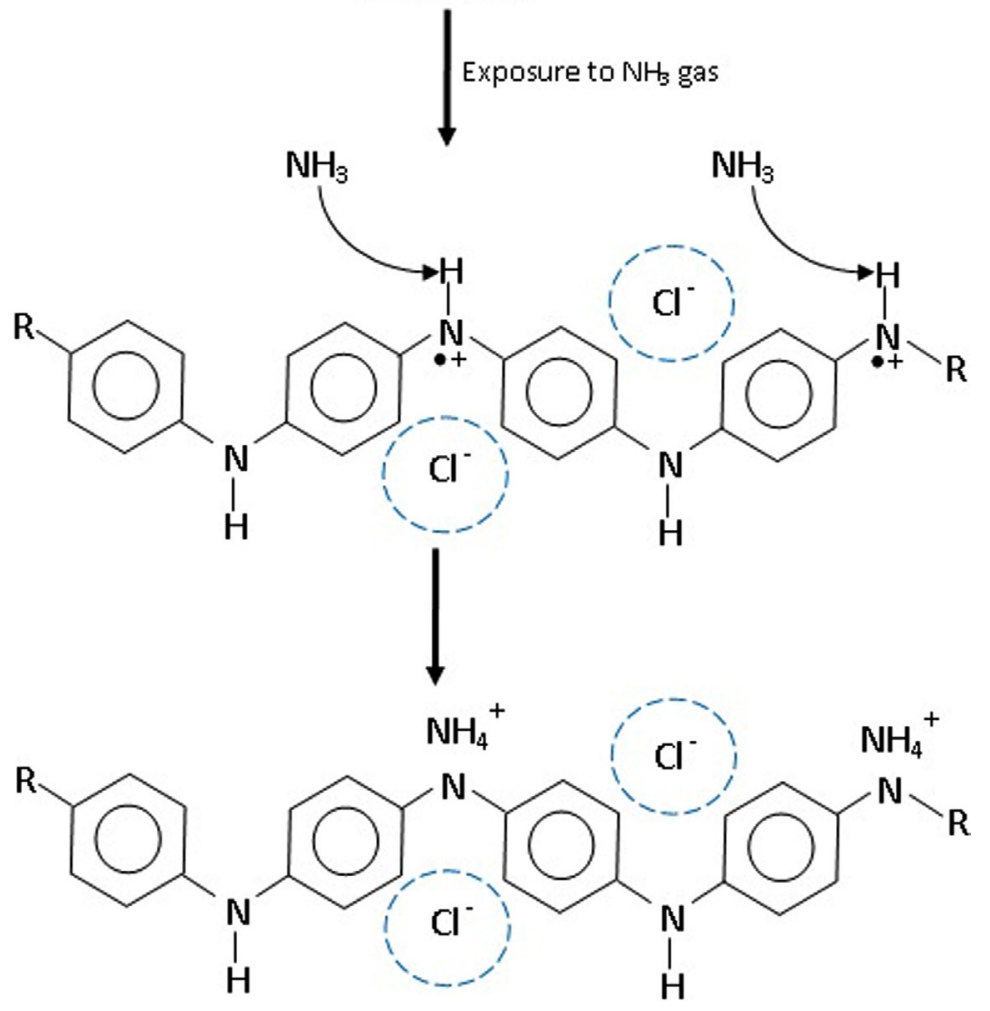

Figure 11: Sensing mechanism of the PMMA/PANI blend on exposure to $\mathrm{NH}_{3}$ gas. 


\section{CONCLUSION}

PMMA/PANI blend nanofibres have been synthesised successfully by electrospinning and dip-coating polymerisation. The formation of PMMA/PANI blend is confirmed by SEM, FTIR and TGA-DTG analysis. The studies of PMMA/ PANI blend as a sensor for $\mathrm{HCl}$ and $\mathrm{NH}_{3}$ gas show sensitivity which increases with the increasing concentration of both the gases. The operating temperature of PMMA/PANI blend for $\mathrm{HCl}$ as well as $\mathrm{NH}_{3}$ gas sensor was found to be near room temperature. These results, along with low response time, confirmed the possible use of the prepared material as a potential candidate for the sensing of $\mathrm{HCl}$ and $\mathrm{NH}_{3}$ gas in the environmental monitoring safety systems, chemical industry, automotive industry and medical application areas.

\section{ACKNOWLEDGEMENTS}

Authors gratefully acknowledge the University Grants Commission (UGC), India for financial assistance provided under the Research Project (39-540/2010-SR) and Department of Science and Technology (DST), India under the DST-FIST Program (SR/FST/PSI-178/2012-C).

\section{REFERENCES}

1. Wang, Y. et al. (2009). Ammonia gas sensor using polypyrrole-coated $\mathrm{TiO}_{2} /$ ZnO nanofibers. Electroanal., 21(12), 1432-1438, http://dx.doi.org/10.1002/ elan.200904584.

2. Chen, S. \& Sun, G. (2013). High sensitivity ammonia sensor using a hierarchical polyaniline/poly(ethylene-co-glycidyl methacrylate) nanofibrous composite membrane. ACS Appl. Mater. Interf., 5(14), 6473-6477, http://dx.doi.org/10.1021/am402217s

3. Kondawar, S. B. et al. (2012). Conductive polyaniline-tin oxide nanocomposites for ammonia sensor. Adv. Mat. Lett., 3(5), 393-398, http://dx.doi.org/10.5185/amlett.2012.6361.

4. Lakard, B. et al. (2015). Review - Gas sensors based on electrodeposited polymers. Metals, 5(3), 1371-1386, http://dx.doi.org/10.3390/met5031371.

5. Bjorn, T. et al. (2005). Ammonia sensors and their applications - A review. Sens. Actuat. B, 107(2), 666-677, http://dx.doi.org/10.1016/j. snb.2004.11.054.

6. Kondawar, S. B. et al. (2014). Chemical vapor sensing properties of electrospun nanofibers of polyaniline/ $\mathrm{ZnO}$ nanocomposites. Adv. Mat. Lett., 5(7), 389-395, http://dx.doi.org/10.5185/amlett.2014.amwc.1037. 
7. Chen, J. et al. (2010). $\mathrm{NH}_{3}$ and $\mathrm{HCl}$ sensing characteristics of polyaniline nanofibers deposited on commercial ceramic substrates using interfacial polymerization. Synth. Met., 160(23), 2452-2458, http://dx.doi. org/10.1016/j.synthmet.2010.09.026.

8. Sharma, H. J. et al. (2015). Electrospun $\mathrm{SnO}_{2} /$ polyaniline composite nanofibers based low temperature hydrogen gas sensor. Fib. Polym., 16(7), 1527-1532, http://dx.doi.org/10.1007/s12221-015-5222-0.

9. Huanga, Z. M. et al. (2003). A review on polymer nanofibers by electrospinning and their applications in nanocomposites. Compos. Sci. Technol., 63(15), 2223-2253, http://dx.doi.org/10.1016/S02663538(03)00178-7.

10. Pethe, S. M. \& Kondawar, S. B. (2014). Optical and electrical properties of conducting polyaniline nanofibers synthesized by interfacial and rapid mixing polymerization. Adv. Mat. Let., 5(12), 728-733, http://dx.doi. org/10.5185/amlett.2014.amwc550.

11. Talwar, V. et al. (2014). $\mathrm{ZnO}$ assisted polyaniline nanofibers and its application as ammonia gas sensor. Sens. Actuat. B Chem., 191, 276-282, http://dx.doi.org/10.1016/j.snb.2013.09.106.

12. Frenot, A. \& Chronakis, I. S. (2003). Polymer nanofibers assembled by electrospinning. Curr. Opin. Coll. Inter. Sci., 8(1), 64-75, http://dx.doi. org/10.1016/S1359-0294(03)00004-9.

13. Huang, J. \& Wan, Q. (2009). Gas sensors based on semiconducting metal oxide one-dimensional nanostructures. Sens., 9(12), 9903-9924, http://doi. org/10.3390/s91209903.

14. Nicolas, D. D. \& Poncin, E. F. (2003). Polyaniline as a new sensitive layer for gas sensors. Anal. Chim. Acta, 475, 1-15, http://doi.org/10.1016/S00032670(02)01229-1.

15. Wang X. et al. (2002). Electrospinning technology: A novel approach to sensor application. J. Macromol. Sci. A, 39(10), 1251-1258, http://doi.org/ doi/abs/10.1081/MA-120014850.

16. Tang, C. C. et al. (2012). Synthesis, structural and gas sensing properties of nanobranched coaxial polyaniline fibers by electrospinning. Adv. Mater. Res., 562, 308-311, http://doi.org/10.4028/www.scientific.net/AMR.562564.308 .

17. Zhang, H. D. et al. (2014). High-sensitivity gas sensors based on arranged Polyaniline/PMMA composite fibers. Sens. Actuat. A Phys., 219, 123-127, http://dx.doi.org/10.1016/j.sna.2014.09.005.

18. Mbese, J. Z. \& Ajibade, P. A. (2014). Preparation and characterisation of $\mathrm{ZnS}, \mathrm{CdS}$ and $\mathrm{HgS} /$ Poly(methyl methacrylate) nanocomposites. Polym., 6(9), 2332-2344, http://doi.org/10.3390/polym6092332. 
19. Garcia, O. P. et al. (2015). Use of lead(II) sulphide nanoparticles as stabilizer for PMMA exposed to gamma irradiation. Mater. Res., 18(2), 365-372, http://dx.doi.org/10.1590/1516-1439.330214.

20. Meneghetti, P. et al. (2004). Synthesis of polymer gel electrolyte with high molecular weight poly(methyl methacrylate)-clay nanocomposite. Electrochim. Acta, 49, 4923-4931, http://dx.doi.org/10.1016/j.electacta. 2004.06.023

21. Buga, M. R. et al. (2015). Surface modification of silk fibroin fibres with poly (methyl methacrylate) and poly(tributylsilyl methacrylate) via RAFT polymerisation for marine antifouling applications. Mater. Sci. Eng. C, 51, 233-241, http://dx.doi.org/10.1016/.msec.2015.03.006.

22. Nguyen, L. H. et al. (2012). Portable cholesterol detection with polyanilinecarbon nanotube film based interdigitated electrodes. Adv. Nat. Sci. Nanosci. Nanotechnol., 3(1), 015004, http://dx.doi.org/10.1088/2043$6262 / 3 / 1 / 015004$.

23. Asha, et al. (2014). Synthesis and characterisation of polyaniline/ $\mathrm{TiO}_{2}$ composites. Ind. J. Pure Appl. Phys., 52, 341-347.

24. Liu, D. et al. (2015). Crosslinked carbon nanotubes/polyaniline composites as a pseudocapacitive material with high cycling stability. Nanomater., 5(2), 1034-1047, http://dx.doi.org/10.3390/nano5021034.

25. Korobeinyk, A. V. et al. (2012). High temperature oxidative resistance of polyacrylonitrile-methylmethacrylate copolymer powder converting to a carbonised monolith. Eur. Polym. J., 48, 97-104, http://dx.doi.org/10.1016/j. cur.polymj.2011.10.006.

26. Valandro, S. R. et al. (2013). Thermal properties of poly(methyl methacrylate)/organomodified montmorillonite nanocomposites obtained by in situ photopolymerization. Mater. Res., 17(1), 265-270. http://dx.doi. org/10.1590/S1516-14392013005000173.

27. Tomar, A. K. et al. (2011). Thermal properties of PMMA doped with polyaniline. AIP Conf. Proc., 1393(1), 145, http://dx.doi.org/10.1063/ 1.3653651.

28. Wang, C. et al. (2010). Metal oxide gas sensors: Sensitivity and influencing factors. Sens., 10(3), 2088-2106, http://dx.doi.org/10.3390/s100302088.

29. Gupta, N. et al. (2006). Advances in sensors based on conducting polymers. J. Sci. Ind. Res., 65, 549-557, http://hdl.handle.net/123456789/4862.

30. Ji, S. et al. (2008). Gas sensing properties of a composite composed of electrospun poly(methyl methacrylate) nanofibers and in situ polymerised polyaniline. Sens. Actuat. B Chem., 133(2), 644-649, http://doi.org/10.1016/j. snb.2008.03.040. 
31. Li, Y. et al. (2016). Highly sensitive $\mathrm{NH}_{3}$ gas sensors based on novel polypyrrole-coated $\mathrm{SnO}_{2}$ nanosheet nanocomposites. Sens. Actuat. B Chem., 224, 449-457. http://doi.org/10.1016/j.snb.2015.10.078.

32. Hong, K. H. et al. (2004). Polyaniline-nylon 6 composite fabric for ammonia gas sensor. J. Appl. Polym. Sci., 92(1), 37-42, http://dx.doi.org/10.1002/ app.13633.

33. Bai, H. \& Shi, G. (2007). Gas sensors based on conducting polymers. Sens., 7(3), 267-307, http://dx.doi.org/10.3390/s7030267.

34. Virji, S. et al. (2004). Polyaniline nanofiber gas sensors: Examination of response mechanisms. Nano Lett., 4(3), 491-496, http://dx.doi.org/10.1021/ n1035122e.

35. Khusp, G. D. et al. (2013). Ammonia gas sensing properties of CSA doped PANi-SnO ${ }_{2}$ nanohybrid thin films. Synth. Met., 185, 1-8, https://doi. org/10.1016/j.synthmet.2013.09.032.

36. Pawar, S. G. et al. (2011) Fabrication of polyaniline/ $/ \mathrm{TiO}_{2}$ nanocomposite ammonia vapor sensor. J. Nanoelectr. Phys., 3, 1056-1063.

37. Guo, Y. et al. (2016) Hierarchical graphene-polyaniline nanocomposite films for high-performance flexible electronic gas sensors, Nanosc., 8, 1207312080, http://dx.doi.org/10.1039/C6NR02540D.

38. Lim, J. H. et al. (2010) Electrical and gas sensing properties of polyaniline functionalized single-walled carbon nanotubes. Nanotechnol., 21(7), 075502-075509. https://doi.org/10.1088/0957-4484/21/7/075502.

39. Patil, S. L. et al. (2011) Fabrication of polyaniline-ZnO nanocomposite gas sensor, Sens. Trans., 134(11), 120-131.

40. Kaushik, A. et al. (2015) Organic-inorganic hybrid nanocomposite-based gas sensors for environmental monitoring. Chem. Rev., 115(11), 4571-4606, https://doi.org/10.1021/cr400659h

41. Kalimuthu, P., Sivanesan, A. \& Abrahum John, S. (2012). Fabrication of optochemical and electrochemical sensors using thin films of porphyrin and phthalocyanine derivatives. J. Chem. Sci., 124(6), 1315-1325. 